\title{
Thermomagnetic analysis of ultramafic rocks: A case study of dunite from the Pekul'ney Complex, Chukotka, NE Russia
}

\author{
K. V. Popov ${ }^{1}$, B. A. Bazylev², V. P. Shcherbakov ${ }^{3,4}$, V. A. Tsel'movich ${ }^{3}$, and N. N. Kononkova ${ }^{2}$ \\ Received 10 February 2015; accepted 20 February 2015; published 31 March 2015.
}

Petromagnetic and thermomagnetic properties of 13 dunite samples from the Pekul'ney Complex in the central Chukotka Peninsula, NE Russia, were measured to gain insight into the potentialities of thermomagnetic techniques in application to studying ultramafic rocks. Dunite currently found in layered tabular ultramafite bodies was produced in the lower crust beneath island arcs or oceanic volcanic arcs and now occurs in tectonic blocks a few kilometers across in the mélange in the axial part of the Pekul'ney Range, which marks the boundary between volcanic complexes. When exhumed, the dunite was affected by a number of episodes of prograde metamorphism, which were associated with the crystallization of metamorphic spinel and magnetite in these rocks. Our data confirm that the temperatures of kinks on the thermomagnetic curves of the natural remanent magnetization of the rocks $I_{n}(T)$ reflect the temperatures of the metamorphic episodes during which ferromagnetic minerals crystallized. Within the range of the possible comparison of temperature estimates obtained for metamorphic recrystallization using magnetic and petrologic techniques (approximately $400-600^{\circ} \mathrm{C}$ ), these estimates for dunite show reasonably good consistence. It is established that the ferromagnetic mineral that crystallized during two metamorphic episodes of the dunite at $530-580$ and $400-460^{\circ} \mathrm{C}$ was low-Cr magnetite. Our data do not indicate that metamorphic spinel can any significantly contribute to the integral magnetization of the rocks. In addition to the two aforementioned episodes of metamorphic recrystallization, our thermomagnetic data on the dunite suggest metamorphic episodes within the temperature ranges of $250-280$ and $170-200^{\circ} \mathrm{C}$. Data obtained in the course of this study are the first to prove simultaneous crystallization of metamorphic Cr-spinel and magnetite whose compositions were not in thermodynamic equilibrium during certain episodes of medium-temperature metamorphic recrystallization of the ultramafic rock, which can be explained by the very low mobility of $\mathrm{Cr}$ in the course of metamorphism. KEYWORDS: Serpentinization; medium-temperature metamorphism; ferrite-chromite; thermomagnetic curves; geothermometer; solid solution; Curie temperature; metamorphic recrystallization.

Citation: Popov, K. V., B. A. Bazylev, V. P. Shcherbakov, V. A. Tsel'movich, and N. N. Kononkova (2015), Thermomagnetic analysis of ultramafic rocks: A case study of dunite from the Pekul'ney Complex, Chukotka, NE Russia, Russ. J. Earth. Sci., 15, ES1003, doi:10.2205/2015ES000547.

\section{Introduction}

\footnotetext{
${ }^{1}$ Shirshov Oceanology Institute, Russian Academy of Sciences, Moscow, Russia

${ }^{2}$ Vernadsky Institute of Geochemistry and Analytical Chemistry (GEOKHI), Moscow, Russia

${ }^{3}$ Borok Geophysical Laboratory, Schmidt Joint Institute of Physics of the Earth, Moscow, Russia

${ }^{4}$ Institute of Geology and Petroleum Technologies, Kazan (Volga region) Federal University, Kazan, Russia
}

Copyright 2015 by the Geophysical Center RAS.

http://elpub.wdcb.ru/journals/rjes/doi/2015ES000547.html
In contrast to basalts and several types of gabbroids, peridotites and dunites are originally paramagnetic rocks because none of their primary minerals are ferromagnetic. These rocks can acquire magnetization if secondary ferromagnetic minerals crystallize in them during their metamorphism, and hence, these exactly minerals can serve as potential sources of petromagnetic and paleomagnetic information. The magnetization of ultramafic rocks is thus closely interrelated with their metamorphic histories. Ultramafites are not very convenient to study as a possible source of 
paleomagnetic information because metamorphism of these rocks, a process that is associated with the crystallization of ferromagnetic minerals, often occurs in more than a single episode, and hence, the rocks receive their magnetization during geologically long enough periods of time [Nguen and Pechersky, 1989. However, this makes petromagnetic characteristics of ultramafites a potential source of information about certain details of their metamorphic history, including information that can hardly be derived by studying these rocks by other techniques. It is traditionally believed that ultramafites acquire their magnetization when affected by serpentinization and related crystallization of magnetite [Dunlop and Prevot, 1982 Popov and Shcherbakova, 1996. However, when petromagnetic characteristics of oceanic peridotites were examined, it was proved that these rocks received their magnetization before the onset of their serpentinization in the course of medium-temperature metamorphism [Bazylev et al., 2002]. The possible ferromagnetic minerals that crystallized during this process are metamorphic Cr-spinel (ferrite-chromite and Cr-bearing magnetite that developed as pseudomorphs after primary Cr-spinel in the ultramafites) and awaruite [Bazylev, 1997, 2000 Bazylev et al., 1990]. To identify the ferromagnetic phase of a rock in a petromagnetic study, thermomagnetic curves of saturation magnetization $I_{s}(T)$ or remanent saturation magnetization $I_{r s}$ are traditionally analyzed in search of the Curie temperature of the ferromagnetic. The only ferromagnetic phase in serpentinized ultramafites is usually magnetite, and the thermomagnetic curves have then a single kink at the Curie temperature of magnetite. However, occasionally thermomagnetic curves $I_{s}(T)$ or $I_{r s}(T)$ of ultramafic rocks (or spinel from them) display kinks below the Curie temperature of magnetite, which provides grounds to think that the rock may contain another ferromagnetic mineral, and the kink temperature is then interpreted as the Curie temperature of this mineral [Kadzialko-Hofmokl et al.,2008 Kudryavtseva, 1988 .

The thermomagnetic curves of natural remanent magnetization of rocks $I_{n}(T)$ are rarely analyzed in petromagnetic studies. However, data derived from thermomagnetic curves of this exactly type enabled us to detect kinks on these curves at temperatures below the Curie temperature of magnetite, which correspond to certain serpentinization episodes of these rocks [Bazylev et al.,2002]. We interpreted the kinks on the $I_{n}(T)$ curves as corresponding to the crystallization temperatures of a ferromagnetic phase produced during certain individual metamorphic episodes [Popov et $a l ., 2006$. We also constrained the probable temperature range of serpentinization of oceanic peridotites and identified the crystallization episodes of a ferromagnetic phase in the rocks at temperatures much higher than the serpentinization temperatures. At the same time, our earlier studies left unsettled certain issues. For example, we suggested that kink temperatures on the $I_{n}(T)$ curves should correspond to the temperatures of episodes of metamorphic recrystallization, and this hypothesis calls for its verification. Also, the nature of the ferromagnetic phase that crystallizes in ultramafites at temperatures above their serpentinization temperatures is so far obscure. It is also still not certain as to what is the contribution of metamorphic Cr-spinel to the integral magnetization of ultramafic rocks and whether the kinks on the $I_{n}(T)$ curves may correspond (at least partly) to the Curie temperatures of the metamorphic Cr-spinel. This study was thus focused on these issues and was carried out using dunite samples from the Pekul'ney Complex in the central Chukotka Peninsula.

\section{Geology, Petrography, and Mineralogy of the Rock Samples}

The submeridional mélange zone in the axial part of the Pekul'ney Range in central Chukotka hosts tectonic blocks a few kilometers across that are made up of orthometamorphic crystalline schists and amphibolites with fragments of banded tabular bodies of cumulus ultramafic rocks. The latter are thought to have been formed in the bottom portion of an island or continental arc. The geology of this area is described in more detail in [Bazylev et al., 2013a. The dunite composes individual beds (ranging from a few dozen to a few hundred meters in thickness) in the ultramafite bodies. The inner structure of the ultramafite bodies is described in detail in [Bazylev et al.,2013b]. The rocks hosting the cumulus ultramafites were affected by regional metamorphism to the epidote-amphibolite facies and also show evidence of retrogression. The latter process also left its footprints in the ultramafites, including the dunite [Bazylev et al., 2013a]. The dunite is dominated by olivine and contains no more than $4 \%$ clinopyroxene and no more than $2.5 \%$ primary Cr-spinel. The $\mathrm{Mg}$ mole fraction $(\mathrm{Mg} \#=100 \times \mathrm{Mg} /(\mathrm{Mg}+\mathrm{Fe}))$ of the olivine varies from 84.0 to 92.3 , and the $\mathrm{Cr}$ mole fraction $(\mathrm{Cr} \#=100 \times \mathrm{Cr} /(\mathrm{Cr}+\mathrm{Al}))$ of the primary spinel is 0.45 0.75 [Bazylev et al., 2013a. The dunite is 30 to $100 \%$ serpentinized. Table 1 presents data on the petrography of the rock and its sampling sites. Olivine in some dunite varieties is locally replaced by coarse-platy (up to $0.5 \mathrm{~mm}$ ) colorless antigorite, but more commonly the olivine is replaced by reticulate veinlets of greenish or brownish, occasionally colorless, fine-flaky serpentine-brucite aggregates, which are optically weakly anisotropic.

Euhedral opaque grains of primary Cr-spinel $0.3-0.8 \mathrm{~mm}$ across are pseudomorphed in margins into metamorphic Crspinel (ferrite-chromite), which is in places overgrown by magnetite. The metamorphic spinel also developed along tiny cracks (as veinlets) cutting across primary Cr-spinel grains. If the primary spinel is completely replaced, the rock contains euhedral ferrite-chromite pseudomorphs after this mineral. If the primary $\mathrm{Cr}$-spinel is replaced by ferrite-chromite, its grains are surrounded by rims of fineplaty $(0.1 \mathrm{~mm})$ colorless chlorite, which is optically weakly anisotropic. In contrast to the primary spinel, whose $\mathrm{Mg}$ mole fraction $\left(100 \times \mathrm{Mg} /\left(\mathrm{Mg}+\mathrm{Fe}^{2+}\right)\right)$ in the dunite is higher than 34 and the degree of Fe oxidation is lower than 0.21 Table 2, the metamorphic Cr-spinel (ferrite-chromite) has a relatively low $\mathrm{Mg}$ mole fraction $(<22)$ and a relatively high degree of Fe oxidation $(>0.21)$. Based on alumina concentration, three populations of the metamorphic Cr-spinel were distinguished, which are thought to have crystallized 
Table 1. Sampling Sites of Rocks and Brief Characteristics of the Petrography of the Rocks and Spinel From Them

\begin{tabular}{|c|c|c|c|c|c|c|c|c|}
\hline no. & Sample & Sampling site (block) & DS & $\mathrm{Ol}$ & Cpx & Spl & $\mathrm{FCr}$ & Mag \\
\hline 1 & NP06-20/1 & Central & 55 & + & + & - & + & + \\
\hline 2 & NP06-51/2 & Vodorazdel'nyi & 100 & - & - & + & + & + \\
\hline 3 & NP06-32/1 & Southern & 50 & + & - & - & - & + \\
\hline 4 & NP06-26/2 & Northern & 60 & + & + & - & + & + \\
\hline 5 & NP06-54/2 & Yanranskii & 35 & + & + & - & + & + \\
\hline 6 & NP06-43/4 & Central & 85 & + & + & + & + & + \\
\hline 7 & NP06-54/3 & Yanranskii & 50 & + & + & + & + & + \\
\hline 8 & NP06-57/2 & Krivorechenskii & 55 & + & + & + & + & + \\
\hline 9 & NP06-20/2 & Central & 45 & + & + & - & - & + \\
\hline 10 & NP06-23/3 & Central & 55 & + & + & - & + & + \\
\hline 11 & NP06-46/2 & Northern & 65 & + & + & + & - & + \\
\hline 12 & NP06-49/2 & Northern & 50 & + & + & + & + & + \\
\hline 13 & NP06-53/2 & Yanranskii & 30 & + & + & + & + & + \\
\hline
\end{tabular}

Note: DS is the degree of serpentinization in \%, mineral symbols: $\mathrm{Ol}$ - olivine, $\mathrm{Cpx}$ - clinopyroxene, Spl - primary Cr-spinel, FCr metamorphic Cr-spinel (ferrite-chromite), Mag - magnetite; signs "+" and "-" denote presence and absence, respectively, in a rock.

successively: 8-13 wt $\% \mathrm{Al}_{2} \mathrm{O}_{3}$ (rare), 1.9-3.7 wt $\% \mathrm{Al}_{2} \mathrm{O}_{3}$ (more widely spread), and $0.08-0.45$ wt $\% \mathrm{Al}_{2} \mathrm{O}_{3}$ (the most ubiquitous) (Table 2). The alumina concentration in the Cr-spinel in association with chlorite and olivine rapidly decreases with decreasing equilibrium temperature [Bazylev et al., 1990. If the compositions of the equilibrium chlorite and olivine are unknown, the metamorphic temperature can be approximately estimated directly from the $\mathrm{Al}_{2} \mathrm{O}_{3}$ concentration in the ferrite-chromite using the formulas calibrated against the olivine-chlorite-spinel geothermometer [Bazylev, 2003 .

According to these evaluations, the ferrite-chromite of the first population crystallized at approximately $600-690^{\circ} \mathrm{C}$, which corresponds to the temperature of the olivine - primary Cr-spinel equilibrium in dunites calculated by the geothermometer [Ballhaus et al., 1991] and also to the maximum temperature of regional metamorphism of the rocks hosting the ultramafic bodies [Bazylev et al., 2013a]. The estimated crystallization temperatures of the second (530 $\left.580^{\circ} \mathrm{C}\right)$ and third $\left(400-460^{\circ} \mathrm{C}\right)$ populations of the ferritechromite correspond to two discrete metamorphic episodes of the rocks during their exhumation. It is important that both of the metamorphic episodes occurred within a temperature range for which crystallization temperatures of ferromagnetics can be independently quantified by thermomagnetic techniques [Popov et al., 2006. Magnetite contained in all of our dunite samples can be classified into populations based on petrographic evidence. Along with the aforementioned rims around grains of primary Cr-spinel and ferritechromite, some of the samples contain large (up to $0.5 \mathrm{~mm}$ ) linear (possibly platy) magnetite segregations along cleavage in olivine grains and along linear contacts between primary olivine grains. The rocks also contain small (less than $5 \mu \mathrm{m}$ ) equant magnetite grains included in olivine. Also, dust of small magnetite grains was detected in cutting serpentinebrucite veinlets replacing olivine, and younger serpentinite veinlets that cut the rocks contain magnetite grains than merge to form large anhedral grains and their aggregates.
The composition of the magnetite can be reliably enough analyzed only if its grains are relatively large $(>10 \mu \mathrm{m})$. The only appreciable admixture in magnetite from the dunite is $\mathrm{Cr}$ (up to 2.5 wt $\% \mathrm{Cr}_{2} \mathrm{O}_{3}$ ), and the concentrations of $\mathrm{NiO}$ (less than 0.4 wt \%), $\mathrm{MgO}$ (less than 0.8 wt \%), and $\mathrm{MnO}$ (less than 0.3 wt \%) are insignificant. The stoichiometry of the magnetite (Table 2) suggests that even if the mineral contains the maghemite end member, its concentration is very low. The fact that the rocks contain various petrographic populations of magnetite led us to suggest that these populations could crystallized at different temperatures, but there are still no mineral thermometers suitable for evaluating these temperatures. Because of this, much importance was attached to the results of thermomagnetic analysis of the dunite. This analysis was carried out using thirteen dunite samples from tectonic blocks that were variably affected by serpentinization and medium-temperature metamorphism, bearing metamorphic Cr-spinel of different composition. We also examined dunite samples containing neither primary nor metamorphic Cr-spinel.

\section{Methods of Petromagnetic Studies and Magnetic Characteristics of the Rocks}

Magnetic properties of the dunite samples were studied at the Borok Geophysical Laboratory, Schmidt Joint Institute of Physics of the Earth, Russian Academy of Sciences. The natural remanent magnetization of rock samples was measured in $1-\mathrm{cm}^{3}$ cubes of the rocks on a JR-6 magnetometer. The coercive characteristics $H_{c}, H_{r c}, I_{s}$, and $I_{s}$ were measured on a Magnetic Measurements Variable Field Translation balance (MMVFTB), and the results are summarized in Table 3.

Our values of the natural remanent magnetization $I_{n}$ measured in the samples are broadly scattered (from 0.34 to 
Table 2. Composition of Primary and Metamorphic Spinel and Magnetite in the Dunite

\begin{tabular}{|c|c|c|c|c|c|c|c|c|}
\hline$\overline{\text { Sample }}$ & NP06-20/1 & NP06-51/2 & NP06-51/2 & NP06-51/2 & NP06-32/1 & NP06-26/2 & NP06-26/2 & NP06-54/2 \\
\hline Population & Met3 & Prim & Met2 & Mag & Mag & Met3 & Mag & Met3 \\
\hline Morphology & Id & Id & Rim1 & Rim2 & Irr & Id & Rim & $\mathrm{Id}$ \\
\hline Anal. spot & 3 & 3 & 3 & 3 & 2 & 5 & 3 & 3 \\
\hline $\mathrm{SiO}_{2}$ & 0.07 & 0.05 & 0.06 & 0.06 & 0.06 & 0.06 & 0.06 & 0.08 \\
\hline $\mathrm{TiO}_{2}$ & 0.80 & 0.25 & 0.31 & 0.01 & 0.60 & 1.30 & 0.13 & 0.33 \\
\hline $\mathrm{Al}_{2} \mathrm{O}_{3}$ & 0.25 & 11.95 & 2.49 & 0.02 & 0.01 & 0.17 & 0.02 & 0.08 \\
\hline $\mathrm{FeO}^{*}$ & 61.08 & 35.98 & 52.37 & 89.96 & 91.80 & 64.91 & 91.11 & 73.92 \\
\hline $\mathrm{MnO}$ & 0.64 & 0.50 & 0.65 & 0.09 & 0.10 & 0.52 & 0.00 & 0.38 \\
\hline $\mathrm{MgO}$ & 1.78 & 6.58 & 3.19 & 0.75 & 0.47 & 1.60 & 0.50 & 0.66 \\
\hline $\mathrm{Cr}_{2} \mathrm{O}_{3}$ & 31.04 & 42.07 & 37.10 & 2.45 & 0.73 & 26.57 & 1.28 & 18.80 \\
\hline $\mathrm{NiO}$ & 0.21 & 0.10 & 0.18 & 0.36 & 0.09 & 0.24 & 0.16 & 0.20 \\
\hline $\mathrm{V}_{2} \mathrm{O}_{3}$ & 0.26 & 0.11 & 0.13 & 0.02 & 0.04 & 0.31 & 0.05 & 0.20 \\
\hline $\mathrm{ZnO}$ & 0.20 & 0.47 & 0.20 & 0.00 & 0.00 & 0.25 & 0.12 & 0.13 \\
\hline Total & 96.32 & 98.08 & 96.68 & 93.69 & 93.86 & 95.92 & 93.41 & 94.79 \\
\hline Total ** & 99.93 & 99.55 & 99.57 & 100.43 & 100.68 & 99.88 & 100.19 & 99.68 \\
\hline $\mathrm{YCr}$ & 0.472 & 0.570 & 0.601 & 0.037 & 0.011 & 0.412 & 0.019 & 0.287 \\
\hline YFe & 0.522 & 0.189 & 0.403 & 0.962 & 0.971 & 0.584 & 0.980 & 0.711 \\
\hline$\underline{T_{C},{ }^{\circ} \mathrm{C}}$ & 138 & -130 & 15 & 548 & 554 & 205 & 560 & 338 \\
\hline Sample & NP06-43/4 & NP06-43/4 & NP06-54/3 & NP06-54/3 & NP06-57/2 & NP06-57/2 & NP06-57/2 & NP06-57/2 \\
\hline Population & Prim & Met2 & Prim & Met2 & Prim & Met1 & Met2 & Mag \\
\hline Morphology & Id & Rim & Id & Rim & Id & Vein & Rim1 & Rim2 \\
\hline Anal. spot & 6 & 2 & 4 & 2 & 6 & 3 & 2 & 1 \\
\hline $\mathrm{SiO}_{2}$ & 0.07 & 0.06 & 0.08 & 0.08 & 0.08 & 0.12 & 0.06 & 0.11 \\
\hline $\mathrm{TiO}_{2}$ & 0.23 & 0.42 & 0.17 & 0.25 & 0.19 & 0.16 & 0.38 & 0.00 \\
\hline $\mathrm{Al}_{2} \mathrm{O}_{3}$ & 16.68 & 3.72 & 15.44 & 1.94 & 19.14 & 12.98 & 3.09 & 0.02 \\
\hline $\mathrm{FeO}^{*}$ & 37.78 & 60.01 & 33.41 & 55.48 & 34.05 & 41.54 & 57.12 & 92.62 \\
\hline $\mathrm{MnO}$ & 0.41 & 0.43 & 0.43 & 0.52 & 0.40 & 0.60 & 0.57 & 0.08 \\
\hline $\mathrm{MgO}$ & 7.09 & 2.18 & 7.92 & 2.43 & 7.13 & 4.24 & 1.93 & 0.29 \\
\hline $\mathrm{Cr}_{2} \mathrm{O}_{3}$ & 36.00 & 29.05 & 40.24 & 34.55 & 37.32 & 38.08 & 32.98 & 0.77 \\
\hline $\mathrm{NiO}$ & 0.15 & 0.34 & 0.19 & 0.35 & 0.10 & 0.09 & 0.19 & 0.35 \\
\hline $\mathrm{V}_{2} \mathrm{O}_{3}$ & 0.16 & 0.22 & 0.10 & 0.10 & 0.17 & 0.16 & 0.20 & 0.04 \\
\hline $\mathrm{ZnO}$ & 0.23 & 0.05 & 0.32 & 0.22 & 0.28 & 0.32 & 0.00 & 0.06 \\
\hline Total & 98.79 & 96.48 & 98.30 & 95.93 & 98.88 & 98.28 & 96.53 & 94.34 \\
\hline Total ** & 100.41 & 99.99 & 99.63 & 99.08 & 100.05 & 99.93 & 99.68 & 100.39 \\
\hline $\mathrm{YCr}$ & 0.472 & 0.427 & 0.530 & 0.513 & 0.485 & 0.524 & 0.487 & 0.012 \\
\hline YFe & 0.201 & 0.491 & 0.167 & 0.444 & 0.144 & 0.215 & 0.444 & 0.988 \\
\hline$\underline{T_{C},{ }^{\circ} \mathrm{C}}$ & -127 & 105 & -135 & 55 & -136 & -122 & 55 & 566 \\
\hline Sample & NP06-20/2 & NP06-23/3 & NP06-46/2 & NP06-49/2 & NP06-49/2 & NP06-53/2 & NP06-53/2 & \\
\hline Population & Mag & Met3 & Prim & Prim* & Met1 & Prim & Met2 & \\
\hline Morphology & Irr & Id & Id & Id & $\operatorname{Rim}$ & Id & Rim & \\
\hline Anal. spot & 2 & 6 & 6 & 5 & 3 & 6 & 4 & \\
\hline $\mathrm{SiO}_{2}$ & 0.07 & 0.07 & 0.06 & 0.07 & 0.07 & 0.07 & 0.09 & \\
\hline $\mathrm{TiO}_{2}$ & 0.06 & 0.76 & 0.26 & 0.22 & 0.57 & 0.39 & 0.57 & \\
\hline $\mathrm{Al}_{2} \mathrm{O}_{3}$ & 0.01 & 0.34 & 25.67 & 20.17 & 8.22 & 23.30 & 1.99 & \\
\hline $\mathrm{FeO}^{*}$ & 92.20 & 60.99 & 31.00 & 32.11 & 49.15 & 32.28 & 61.38 & \\
\hline $\mathrm{MnO}$ & 0.30 & 0.50 & 0.30 & 0.39 & 0.59 & 0.39 & 0.49 & \\
\hline $\mathrm{MgO}$ & 0.26 & 1.68 & 9.37 & 7.41 & 3.01 & 7.62 & 1.52 & \\
\hline $\mathrm{Cr}_{2} \mathrm{O}_{3}$ & 0.23 & 31.83 & 31.13 & 37.81 & 34.89 & 34.70 & 30.46 & \\
\hline $\mathrm{NiO}$ & 0.10 & 0.16 & 0.17 & 0.11 & 0.16 & 0.11 & 0.03 & \\
\hline $\mathrm{V}_{2} \mathrm{O}_{3}$ & 0.17 & 0.22 & 0.17 & 0.21 & 0.23 & 0.20 & 0.17 & \\
\hline $\mathrm{ZnO}$ & 0.00 & 0.22 & 0.22 & 0.42 & 0.22 & 0.34 & 0.14 & \\
\hline Total & 93.38 & 96.79 & 98.34 & 98.92 & 97.12 & 99.41 & 96.82 & \\
\hline Total ** & 100.26 & 100.34 & 99.41 & 99.91 & 99.48 & 100.37 & 100.37 & \\
\hline YCr & 0.003 & 0.481 & 0.390 & 0.489 & 0.501 & 0.442 & 0.455 & \\
\hline $\mathrm{YFe}$ & 0.996 & 0.511 & 0.131 & 0.123 & 0.323 & 0.116 & 0.501 & \\
\hline$T_{C},{ }^{\circ} \mathrm{C}$ & 571 & 126 & -136 & -135 & -56 & -134 & 115 & \\
\hline
\end{tabular}

Note: Prim - primary Cr-spinel, Met - metamorphic Cr-spinel, (ferrite-chromite) of various populations, Mag - magnetite. Id euhedral grains or their cores, Rim - homogeneous rim around euhedral grains, Rim1 - inner rim, Rim2 - outer rim, Irr - anhedral grains, Vein - veinlet cutting across the core of an euhedral grain. FeO* - all Fe in the form of FeO. Total** - total of oxides after recalculation of part of $\mathrm{FeO}^{*}$ into $\mathrm{Fe}_{2} \mathrm{O}_{3}$ based on stoichiometric considerations for spinel (that is presumed to contain no structural vacancies). $\mathrm{YCr}-\mathrm{Cr} /\left(\mathrm{Cr}+\mathrm{Al}+\mathrm{V}+\mathrm{Fe}^{3+}\right), \mathrm{YFe}-\mathrm{Fe}^{3+} /\left(\mathrm{Cr}+\mathrm{Al}+\mathrm{V}+\mathrm{Fe}^{3+}\right)$. Minerals were analyzed on a $\mathrm{Cameca}$ SX-100 microprobe at the Vernadsky Institute in polished petrographic thin sections in compliance with the conventionally used techniques [see Bazylev et al., 2013a for details of the analytical procedure]. $T_{C}$ - Curie temperature of spinel evaluated from its composition using the compositional dependence in [Ziemniak and Castelli,2003]. The asterisk marks the spinel composition compiled from [Bazylev et al., 2013a]. 
Table 3. Magnetic Characteristics of the Dunite Samples

\begin{tabular}{|c|c|c|c|c|c|c|c|c|c|c|c|c|}
\hline Sample & $\begin{array}{c}I_{n}, \\
\mathrm{~A} / \mathrm{m}\end{array}$ & $\begin{array}{l}\chi, 10^{-3} \\
\text { SI units }\end{array}$ & $\mathrm{Q}$ & $I_{r s} / I_{s}$ & $\begin{array}{c}I_{s} \\
10^{3} \mathrm{~A} / \mathrm{m}\end{array}$ & $\begin{array}{c}I_{r s} \\
10^{3} \mathrm{~A} / \mathrm{m}\end{array}$ & $\begin{array}{l}H_{c} \\
\mathrm{mT}\end{array}$ & $\begin{array}{l}H_{r c}, \\
\mathrm{mT}\end{array}$ & $H_{r c} / H_{c}$ & $\begin{array}{c}T_{c}\left(I_{s}\right) \\
{ }^{\circ} \mathrm{C}\end{array}$ & $I_{s t} / I_{s o}$ & $\begin{array}{c}C, \\
\text { vol } \%\end{array}$ \\
\hline NP06-20/1 & 18.4 & 67.3 & 7.0 & 0.09 & 5.7 & 0.53 & 7.1 & 17.8 & 2.5 & 595 & 0.44 & 1.26 \\
\hline NP06-51/2 & 4.5 & 57.7 & 1.98 & 0.08 & 3.26 & 0.24 & 5.8 & 16.4 & 2.8 & 590 & 0.60 & 0.72 \\
\hline NP06-32/1 & 2.6 & 88.0 & 0.75 & 0.19 & 4.4 & 0.82 & 12.0 & 24.3 & 2.0 & 590 & 0.45 & 0.97 \\
\hline NP06-26/2 & 0.9 & 70.4 & 0.03 & 0.16 & 4.34 & 0.69 & 11.7 & 22.6 & 1.9 & 595 & 0.45 & 0.96 \\
\hline NP06-54/2 & 3.9 & 110. & 0.9 & 0.10 & 8.96 & 0.93 & 7.2 & 15.8 & 2.18 & 600 & 0.45 & 1.99 \\
\hline NP06-43/4 & 21.0 & 49.0 & 10.9 & 0.14 & 4.65 & 0.64 & 9.6 & 18.5 & 1.92 & 600 & 0.46 & 1.03 \\
\hline NP06-54/3 & 1.6 & 20.1 & 2.1 & 0.12 & 1.10 & 0.13 & 7.6 & 16.0 & 2.11 & 595 & 0.39 & 0.24 \\
\hline NP06-57/2 & 1.4 & 32.6 & 1.1 & 0.13 & 4.38 & 0.58 & 9.4 & 20.8 & 2.22 & 600 & 0.61 & 0.97 \\
\hline NP06-20/2 & 135 & 109. & 31.5 & 0.11 & 11.26 & 1.27 & 7.9 & 18.4 & 2.33 & 595 & 0.63 & 2.50 \\
\hline NP06-23/3 & 0.34 & 37.9 & 0.2 & 0.13 & 3.59 & 0.48 & 9.6 & 20.3 & 2.12 & 600 & 0.59 & 0.79 \\
\hline NP06-46/2 & 4.6 & 49.2 & 2.4 & 0.16 & 4.41 & 0.71 & 11.2 & 20.6 & 1.83 & 595 & 0.52 & 0.98 \\
\hline NP06-49/2 & 13.6 & 47.1 & 7.4 & 0.23 & 4.54 & 1.04 & 13.0 & 19.6 & 1.5 & 595 & 0.41 & 1.00 \\
\hline NP06-53/2 & 7.8 & 58.4 & 3.1 & 0.13 & 4.7 & 0.58 & 8.6 & 18.3 & 2.14 & 595 & 0.50 & 1.04 \\
\hline
\end{tabular}

Note: $I_{n}$ - natural remanent magnetization; $\chi$ - magnetic susceptibility; $Q$ - Koenigsberger ratio; $I_{s}$ - saturation magnetization; $I_{r s}$ - remanent saturation magnetization; $H_{c}$ - coercive force; $H_{r c}$ - remanent coercive force; $T_{c}$ - Curie temperature for magnetite; $I_{s t} / I_{s o}$ - ratio of the saturation magnetization of the sample after its heating to $700^{\circ} \mathrm{C}$ to its initial saturation magnetization; $C$ volumetric percentage of magnetite in the sample calculated from the saturation magnetization value $I_{s}$.

135.7 A/m) at an average of $16.7 \mathrm{~A} / \mathrm{m}$. The magnetic susceptibility $\chi$ values vary within a somewhat narrower range of $20.1 \times 10^{-3}$ to $110.0 \times 10^{-3}$ SI units at an average of $61.3 \times 10^{-3}$ SI units. The magnetic susceptibility of the samples is weakly correlated with their natural remanent magnetization: the correlation coefficient is 0.52 . The Koenigsberger ratio $\mathrm{Q}$ averages at 5.3 and thereby varies from 0.03 to 31.5 ; $\mathrm{Q}$ values greater than one for most of the samples testify to stability of their natural remanent magnetization $I_{n}$. The saturation magnetization $I_{s}$ of the samples varies within one order of magnitude and is $5.02 \times 10^{3} \mathrm{~A} / \mathrm{m}$ on average. Theoretically, this magnetic parameter provides the most unbiased information on the content of a ferromagnetic phase in the rock. The elevated $\left(590-600^{\circ} \mathrm{C}\right)$ Curie temperature and $I_{s t} / I_{\text {so }}$ ratio of close to 0.5 suggest a singlephase oxidation of magnetite grains in the samples, i.e., that the dominant ferromagnetic phase of the rocks is magnetitemaghemite solid solution $\gamma \mathrm{Fe}_{2} \mathrm{O}_{3}$. The magnetite mole fraction in this solid solution evaluated from the Curie temperature and using the diagram from [Readman and O'Reilly, 1972 is approximately 0.8. In compliance with this, we evaluated the spontaneous magnetization of ferromagnetic of this composition at $4.85 \times 10^{5} \mathrm{~A} / \mathrm{m}$. The corresponding calculated contents of the ferromagnetic phase in the samples are listed in Table 3 and are 1.1 vol \% on average. Some of the magnetic parameters reflect the domain state of the ferromagnetic and the size of its grains. For instance, the ratio of the remanent magnetization to the saturation magnetization $I_{r s} / I_{s}$, which averages at 0.14 for our samples, suggests that the ferromagnetic grains are in a pseudo-single-domain state. The remanent coercive force $H_{c r}$, which is $19.2 \mathrm{mT}$ on average, is also typical of pseudo-single-domain grains [Shcherbakov et al., 1996].

\section{Methods and Results of Thermomagnetic Analysis}

The thermomagnetic curves of the temperature dependence of the saturation magnetization $I_{s}(T)$ were examined on a Vinogradov variometer. The samples $(\sim 30 \mathrm{mg})$ were heated in a field of 6000 Oe. Magnetization was recorded to a temperature of $700^{\circ} \mathrm{C}$, in temperature incremental steps of $0.1^{\circ} \mathrm{C}$. Upon cooling the samples to room temperature, they were reheated also to $700^{\circ} \mathrm{C}$ to identify the nature of the kinks. A kink on a thermomagnetic curve was assumed to be a segment of the curve with a loss of part of the magnetization of the sample and a change in the demagnetization path. Theoretically, kinks on the temperature functions of the magnetization curves correspond to a change in the sign of the derivative of $I(T)$ and a maximum of the second derivative $d^{2} I / d T^{2}$ of this dependence. The corresponding calculations were carried out with our original SPLAIN software. The results are graphically represented in Figure 1.

In principle, the fact that the reheating curves $I_{s 2}(T)$ show kinks at temperatures close to those on the first-heating curves suggests that this is indeed the Curie temperature corresponding to a certain magnetic phase contained in the sample. Laboratory heating of a rock may sometimes be associated with the partial decomposition of its silicates with the segregation of ferromagnetic grains, which are magnetized in this field. In this instance, kinks may be formed on the thermomagnetic curves, with these kinks usually significantly differing in temperature and being actually artifacts. We studied the dependence of the natural remanent magnetization of the sample on temperature $I_{n}(T)$ on a twocomponent magnetometer. 


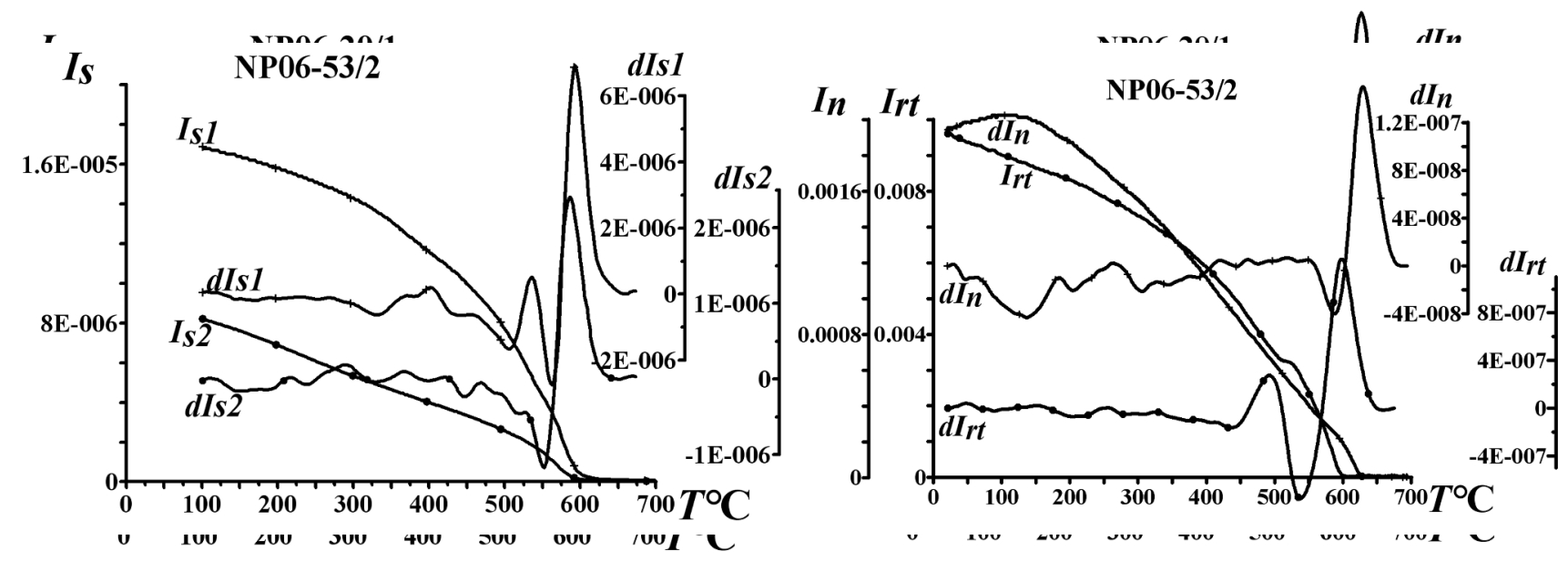

Figure 1. Thermomagnetic curves showing the temperature dependencies of saturation magnetization (left-hand plots). $I_{s 1}$ and $I_{s 2}$ are the first and second heating, respectively. $I_{n}$ is the thermomagnetic curves of natural remanent magnetization. $I_{r t}$ is the thermomagnetic curves of thermal remanent magnetization (right-hand plots). For each curve, curves of its second derivative are shown, and the temperatures of kinks on the curves of natural remanent magnetization are presented. The values of $I_{s}$, $I_{n}$, and $I_{r t}$ are in $10^{3} \mathrm{~A} / \mathrm{m}$. To select sample click on the corresponding number in red square. Samples: a - NP06-20/1, b - NP06-51/2, c - NP06-32/1, d - NP06-26/2, e - NP06-54/2, f - NP06-43/4, g - NP06-54/3, h - NP06-57/2, i - NP06-20/2, $\mathbf{j}$ - NP06-23/3, | k - NP06-46/2, $\mathbf{l}-\mathrm{NP06}-49 / 2$, m- NP06-53/2.

The thermomagnetic curve was recorded when the sample was heated to $700^{\circ} \mathrm{C}$, a process associated with $I_{n}$ destruction. The sample was then cooled in a magnetostatic field of 0.5 Oe. When cooled, the sample acquired thermoremanent magnetization $I_{r t}$. When reheating the sample, we recorded the thermomagnetic curve of thermoremanent magnetization $I_{r t}(T)$. It was hypothesized [Popov et al., 2006] that kinks on $I_{n}(T)$ curves may be explained by the loss of the partial thermoremanent magnetization of the ferromagnetic phase when its crystallization temperature is reached; this loss is irreversible, and hence, kinks on the $I_{n}(T)$ curve are not reproduced on the $I_{r t}(T)$ curve at corresponding temperatures.

The occurrence of kinks on the $I_{r t}(T)$ curve at temperatures at which no kinks occur on the $I_{n}(T)$ curve can be interpreted as a consequence of weak heating, i.e., as an artifact. The occurrence of kinks on both curves at similar temperatures can stem from the fact that the sample contains a ferromagnetic phase whose Curie temperature corresponds to the kink temperature, and in this instance, kinks at similar temperatures may also be registered on the thermal saturation magnetization curves. The main kinks on the thermomagnetic curves of saturation magnetization of all samples lie within the range of $590-600^{\circ} \mathrm{C}$, which corresponds to the Curie temperature of the dominant ferromagnetic phase (partly oxidized magnetite). Some of our thermomagnetic curves show noticeable kinks (1-2) at lower temperature. The thermomagnetic curves of natural remanent magnetization display a main kink at $630-650^{\circ} \mathrm{C}$, which obviously corresponds to the Curie temperature of partly oxidized magnetite, similar to the thermomagnetic curves of saturation magnetization. The much higher temperatures of this kink on the $I_{n}(T)$ curves may be explained by the fact that the dominant contribution to the natural remanent magnetization of the rocks is made by the smallest grains, whereas the saturation magnetization measured in a strong magnetic field is caused by all grains contained in the rock, regardless of their size (Paleomagnetology, petromagnetology, and geology: A glossary as a handbook for neighbors in profession, http://paleomag.ifz.ru/books/PPG-dictionary2010.pdf). Hence, higher temperatures of kinks on the $I_{n}(T)$ thermomagnetic curves may reflect a higher degree of oxidation of the smallest magnetite grains. In addition to the main kink, the thermomagnetic curves of natural remanent magnetization of our samples show two to five less intense kinks within the temperature range of $140-570^{\circ} \mathrm{C}$. The thermomagnetic curves of remanent magnetization of most of our samples usually have only one kink at a temperature close to $480^{\circ} \mathrm{C}$, along with the main kink at the Curie temperature of oxidized magnetite (at $580-600^{\circ} \mathrm{C}$ ). One of our samples (NP06-51/2) displays no this additional kink, and sample NP06-57/2 has instead two kinks: at 410 and $530^{\circ} \mathrm{C}$. 


\section{Discussion}

\section{Specifics of Petromagnetic Parameters of the Dunite}

Although the dunite was metamorphosed and serpentinized in a geological environment different from that in mid-oceanic ridges, and olivine from the rock exhibits a much broader range of its $\mathrm{Mg}$ mole fraction (84.0-92.3) [Bazylev et al., 2013a than that of olivine in oceanic peridotites, most petromagnetic characteristics of our dunite samples do not have any significant differences from the petromagnetic characteristics of peridotites studied earlier by ourselves [Bazylev et al., 2002] and other researchers [Nazarova et al., 2000]. For example, the mean saturation magnetization of our dunite samples $\left(5.02 \times 10^{3} \mathrm{~A} / \mathrm{m}\right)$ is practically identical to that of peridotites from mid-oceanic ridges $\left(4.5 \times 10^{3} \mathrm{~A} / \mathrm{m}\right)$ [Bazylev et al., 2002 and is closely similar to the mean magnetization of peridotites from the Gorringe Ridge $\left(6.71 \times 10^{3} \mathrm{~A} / \mathrm{m}\right)$ [Popov et al., 2011]. Correspondingly, the average magnetite contents of these rocks should also be similar. The most remarkable differences likely occur in the remanent coercive force per magnetization Hrc, which is $19.2 \mathrm{mT}$ in our samples and $31.4 \mathrm{mT}$ on average in oceanic peridotites [Popov et al., 2011]. This parameter reflects the domain state and integral grain size of the ferromagnetic in the rock, and its value testifies that ferromagnetic grains in our dunite samples are generally somewhat larger than in oceanic peridotites and occur in a pseudo-single-domain state, whereas ferromagnetic grains in oceanic peridotites are predominantly in a single-domain state. A relatively large integral grain size of ferromagnetic is typically produced by medium-temperature metamorphic recrystallization, in contrast to serpentinization, which results mostly in small ferromagnetic grains [Bazylev et al., 2002. Hence, this difference may reflect a higher intensity of medium-temperature metamorphic recrystallization of the dunite in question compared to oceanic peridotites.

\section{Interpretation of Thermomagnetic Data}

For convenience of interpreting the thermomagnetic data, the kink temperatures on the thermomagnetic curves are graphically represented in Figure 1 and summarized in Table 4 .

The temperatures of kinks on the saturation magnetization curve are usually not reproduced at reheating. It is pertinent to mention certain similarities between the kink temperatures of samples NP06-46/2 (540 and $520^{\circ} \mathrm{C}$ ) and NP06-54/2 (395 and $\left.425^{\circ} \mathrm{C}\right)$. However, bearing in mind that the difference between the kink temperatures on the $I_{s 1}(T)$ and $I_{s 2}(T)$ corves for oxidized magnetite in all samples does not exceed $10^{\circ} \mathrm{C}$, it is hardly possible that the temperatures of the kinks (differences of $20-30^{\circ} \mathrm{C}$ ) correspond to the Curie temperature of any other ferromagnetic phase contained in the sample. Similarities of the kink temperatures on the $I_{n}$ and $I_{r t}$ curves were detected only in sample NP06-57/2
Table 4. Temperatures of Kinks on the Thermomagnetic Curves of our Samples

\begin{tabular}{|c|c|c|c|c|}
\hline \multirow[t]{2}{*}{ Sample } & \multicolumn{2}{|c|}{$\begin{array}{c}\text { Saturation } \\
\text { magnetization } \\
\text { curves }\end{array}$} & \multicolumn{2}{|c|}{$\begin{array}{c}\text { Natural remanent } \\
\text { magnetization } \\
\text { curves }\end{array}$} \\
\hline & $I_{s 1}$ & $I_{s 2}$ & $I_{n}$ & $I_{r t}$ \\
\hline NP06-20/1 & 595 & 590 & $\begin{array}{l}190 \\
420 \\
540 \\
645 \\
\end{array}$ & $\begin{array}{l}460 \\
600 \\
\end{array}$ \\
\hline NP06-51/2 & 590 & 590 & $\begin{array}{l}170 \\
400 \\
560 \\
655\end{array}$ & 590 \\
\hline NP06-32/1 & 590 & 590 & $\begin{array}{l}175 \\
275 \\
435 \\
550 \\
630 \\
\end{array}$ & $\begin{array}{l}500 \\
590 \\
\end{array}$ \\
\hline NP06-26/2 & $\begin{array}{l}385 \\
530 \\
595 \\
\end{array}$ & $\begin{array}{l}340 \\
430 \\
590 \\
\end{array}$ & $\begin{array}{l}220 \\
280 \\
375 \\
445 \\
550 \\
635 \\
\end{array}$ & $\begin{array}{l}490 \\
600 \\
\end{array}$ \\
\hline NP06-54/2 & $\begin{array}{l}395 \\
540 \\
600\end{array}$ & $\begin{array}{c}320 \\
425 \\
595 ?\end{array}$ & $\begin{array}{c}235 \\
440 \\
535 ? \\
635\end{array}$ & $\begin{array}{l}500 \\
595\end{array}$ \\
\hline NP06-43/4 & $\begin{array}{l}390 \\
600 \\
\end{array}$ & $\begin{array}{c}295 \\
595 ? \\
\end{array}$ & $\begin{array}{l}185 \\
550 \\
670 \\
\end{array}$ & $\begin{array}{l}475 \\
600 \\
\end{array}$ \\
\hline NP06-54/3 & $\begin{array}{l}400 \\
595\end{array}$ & $\begin{array}{l}300 \\
595\end{array}$ & $\begin{array}{l}140 \\
540 \\
640\end{array}$ & $\begin{array}{l}470 \\
600\end{array}$ \\
\hline NP06-57/2 & 600 & 600 & $\begin{array}{l}265 \\
415 \\
560 \\
635 \\
\end{array}$ & $\begin{array}{l}400 \\
530 \\
580 \\
\end{array}$ \\
\hline NP06-20/2 & 595 & 595 & $\begin{array}{l}250 \\
460 \\
555 \\
630\end{array}$ & $\begin{array}{l}500 \\
595\end{array}$ \\
\hline NP06-23/3 & $\begin{array}{l}385 \\
540 \\
600 \\
\end{array}$ & $\begin{array}{l}320 \\
470 \\
600 \\
\end{array}$ & $\begin{array}{c}265 \\
415 \\
560 ? \\
645 \\
\end{array}$ & $\begin{array}{l}500 \\
590 \\
\end{array}$ \\
\hline NP06-46/2 & $\begin{array}{l}375 \\
540 \\
595 \\
\end{array}$ & $\begin{array}{l}335 \\
520 \\
595 \\
\end{array}$ & $\begin{array}{c}250 \\
570 ? \\
655\end{array}$ & $\begin{array}{l}485 \\
595\end{array}$ \\
\hline NP06-49/2 & $\begin{array}{l}400 \\
520 \\
595 \\
\end{array}$ & $\begin{array}{l}375 \\
485 \\
595\end{array}$ & $\begin{array}{l}255 \\
420 \\
570 \\
640\end{array}$ & $\begin{array}{l}480 \\
590\end{array}$ \\
\hline NP06-53/2 & $\begin{array}{l}400 \\
535 \\
595\end{array}$ & $\begin{array}{l}300 \\
470 \\
595\end{array}$ & $\begin{array}{l}260 \\
540 \\
630\end{array}$ & $\begin{array}{l}500 \\
600\end{array}$ \\
\hline
\end{tabular}




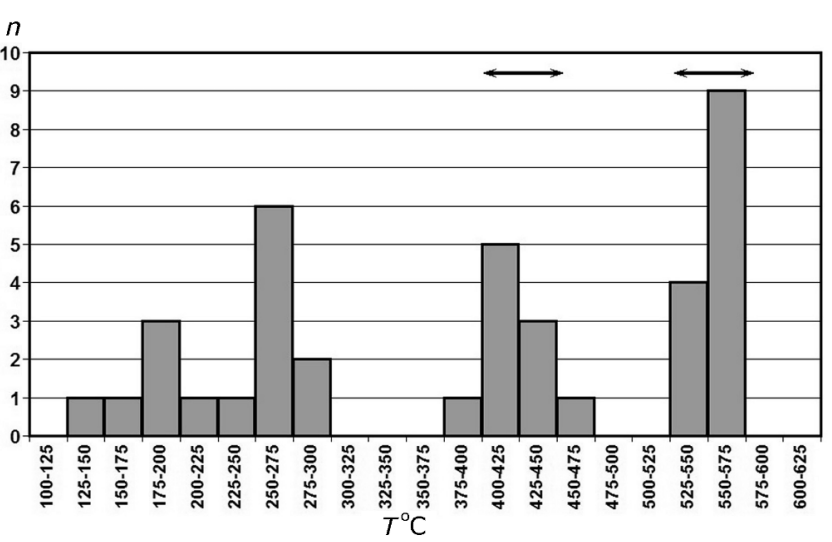

Figure 2. Histogram of kink temperatures on the thermomagnetic curves of the natural remanent magnetization $I_{n}(T)$ of our samples (based on data in Table 4); $n$ is the number of kinks. Arrows show the temperature ranges of the metamorphic recrystallization of the dunite calculated from the composition of its metamorphic Cr-spinel.

(415 and $410^{\circ} \mathrm{C}, 560$ and $530^{\circ} \mathrm{C}$ ), but the thermomagnetic curves for the saturation magnetization of this sample have no kinks at these temperatures. This led us to interpret the similarities of the kink temperatures in this situation not as reflecting the Curie temperatures of certain ferromagnetic phases but as a coincidence. Nevertheless, to test this hypothesis, we attempted to evaluate the Curie temperatures for primary and metamorphic Cr-spinel in our samples and for the magnetite from their compositions by the dependence in [Ziemniak and Castelli, 2003]. The calculation results are presented in Table 2 and testify that the Curie temperatures of metamorphic Cr-spinel in the samples are no higher than $340^{\circ} \mathrm{C}$. It is thus highly probable that all of the aforementioned similarities between the kink temperatures on various thermomagnetic curves are coincidental and thus cannot be interpreted as corresponding to the Curie temperatures of any ferromagnetic phases. At the same time, the absence of kinks at analogous temperatures on both thermomagnetic curves of the saturation magnetization for the six samples for which the calculated Curie temperatures of their metamorphic Cr-spinel lie within the range of $50-340^{\circ} \mathrm{C}$ (which should had been reflected in the configurations of these curves) testifies that the contribution of metamorphic Cr-spinel to the integral magnetization of rocks in our samples is negligibly small compared to the contribution of magnetite. Primary Cr-spinel does not contribute to the magnetization of the rocks because its evaluated Curie temperatures are much lower than $0^{\circ} \mathrm{C}$ (Table 2 ). All facts and considerations presented above led us to interpret the temperatures of kinks on the thermomagnetic curves of natural remanent magnetization for the dunite as the temperatures of metamorphic episodes that were associated with magnetite crystallization.

The histograms of these temperatures (Figure 2 show four clearly pronounced peaks. The two highest temperature peaks (at $525-575$ and $400-450^{\circ} \mathrm{C}$ ) can be reliably correlated with the two episodes of medium-temperature metamorphism that are reflected in the composition of the metamorphic spinel (at approximately 530-580 and 400$460^{\circ} \mathrm{C}$, respectively). The two temperature peaks at 250 275 and $174-200^{\circ} \mathrm{C}$ likely mark two discrete serpentinization episodes. The closely similar temperature values of the metamorphic recrystallization of the dunite evaluated by petrologic and petromagnetic techniques illustrate the reliability of the thermomagnetic techniques and their applicability in estimating the temperatures of metamorphic recrystallization of ultramafites. Thereby the petromagnetic thermometric techniques are proved to be more sensitive than the petrologic techniques: thermomagnetic techniques make it possible to reveal both high-temperature metamorphic episodes in nine of our thirteen samples, whereas the composition of the metamorphic spinel in all of the samples provides evidence only of one of the two episodes.

\section{Petrological Aspects of Metamorphism in Dunite}

Similarities between the temperature estimates of certain metamorphic episodes obtained using petrological techniques (deduced from the composition of the metamorphic Cr-spinel) and derived from kinks on the thermomagnetic curves of the natural remanent magnetization (caused by magnetite) undoubtedly testify that the episodes of dunite recrystallization at $525-575$ and $400-450^{\circ} \mathrm{C}$ were associated with the simultaneous crystallization of metamorphic $\mathrm{Cr}$ spinel and magnetite in the rocks. This is a fairly nontrivial conclusion. On the one hand, the magnetite-chromite series should have a miscibility gap at these temperatures [Sack and Ghiorso, 1991] Ziemniak and Castelli, 2003, but no such phenomenon was detected in Cr-spinel from the dunite, and the composition data points of the mineral (Table 2) bridge the miscibility gap (it should be mentioned that the solvus configurations are slightly different in the papers quoted above). The magnetite is too poor in $\mathrm{Cr}$ to be in thermodynamic equilibrium with the ferrite-chromite. On the other hand, metamorphism of oceanic peridotites is characterized not by overall equilibrium but merely local one [Bazylev et al., 1990], which is pronounced in the compositional variability of the same metamorphic minerals when occurring in different associations and structural settings in a rock, as is particularly well pronounced in the differences in the $\mathrm{Cr}$ concentrations in the metamorphic silicates [Bazylev, 2003. A possible reason for local equilibrium may have been the limited mobility of certain elements (first of all $\mathrm{Cr}$ ) in the course of medium- and low-temperature metamorphism, as is illustrated by the pseudomorphic character of metamorphic recrystallization typical of the dunite. Hence, the simultaneous crystallization of magnetite and metamorphic Cr-spinel in the dunite can be explained by the very low mobility of $\mathrm{Cr}$, which could migrate within the volumes of primary Cr-spinel grains and their closest vicinities. 


\section{Distinguishing Features of Metamorphism in Various Tectonic Blocks of the Complex}

Two highest temperature metamorphic episodes of those shown in the histogram in Figure 2 affected dunite samples from all tectonic blocks of the complex. These episodes likely mark the early tectonic exhumation of rocks of the Pekul'ney Complex, when the latter still was not tectonically disintegrated into blocks. The later metamorphic histories of dunite in the various blocks were somewhat different. For example, the metamorphic episode at $250-275^{\circ} \mathrm{C}$ left its footprints in dunite samples from all blocks except only the Vodorazdel'nyi one, whereas the recrystallization episode at $175-200^{\circ} \mathrm{C}$ is discernible in dunite from all blocks except the Krivorechenskii one. The materials and considerations presented above show that the application of petromagnetic techniques in studying ultramafic rocks may provide certain valuable geological information.

\section{Conclusions}

1. The results of our study confirm that the temperatures of kinks on the thermomagnetic curves of natural remanent magnetization of rocks $I_{n}(T)$ reflect the temperatures of metamorphic episodes that were associated with the crystallization of a ferromagnetic mineral. Within the range of the possible correlation of temperature estimates obtained for the metamorphic recrystallization of rocks using petromagnetic and petrologic techniques (approximately $400-600^{\circ} \mathrm{C}$ ), such estimates for our dunite samples are reasonably consistent.

2. Our results prove that the ferromagnetic mineral that crystallized in the course of the two metamorphic episodes in the dunite at $530-580$ and $400-460^{\circ} \mathrm{C}$ was $\mathrm{Cr}$-poor magnetite but not metamorphic spinel, whose calculated Curie temperatures are no higher than $340^{\circ} \mathrm{C}$.

3 . The fact that the thermomagnetic curves of saturation magnetization for our dunite samples $I_{s 1}(T)$ and $I_{s 2}(T)$ exhibit no kinks at the same temperatures, which could have been interpreted as the Curie temperatures of the metamorphic Cr-spinel, testifies that the contribution of metamorphic spinel to the integral magnetization of the rocks is negligibly small (no greater than a few percent). This led us to interpret the discrete temperature ranges of the kinks on the thermomagnetic curves of remanent magnetization of the rocks $I_{n}(T)$ at $250-280$ and $170-200^{\circ} \mathrm{C}$ as the temperatures of discrete episodes of low-temperature recrystallization of the rocks. This fact rules out the interpretation of these temperatures as reflecting the Curie temperatures of the metamorphic Cr-spinel.

4. Our results are the first to prove simultaneous crystallization of metamorphic Cr-spinel and magnetite of thermodynamically unequilibrated composition in the course of discrete episodes of medium-temperature metamorphic recrystallization of the ultramafic rocks. The unequilibrated character of the compositions of these minerals can be explained by the very low mobility of Cr during metamorphism.
Acknowledgment. The work was supported by Governmental contract No. 0149-2014-0031 and supported by the Russian Foundation for Basic Research (RFFI), grant 15-05-04543.

\section{References}

Ballhaus, C., R. F. Berry, D. H. Green (1991), High pressure experimental calibration of the olivine-orthopyroxene-spinel oxygen geobarometer: implications for the oxidation state of the upper mantle, Contrib. Mineral. Petrol., 107, 27-40. doi:10.1007/BF00311183

Bazylev, B. A. (1997), Allochemical metamorphism of mantle peridotites in the Hayes Fracture Zone of the North Atlantic, Petrology, 5, No. 4, 322-337.

Bazylev, B. A. (2000), Awaruite containing mineral association abundance in peridotite of the fault zone $15^{\circ} 20^{\prime}$ (the Atlantic ocean) as one of the manifestations of oceanic metamorphism, Russ. J. Earth Sci., 2, No. 3, 279-293. (in Russian) doi:10.2205/2000ES000045

Bazylev, B. A. (2003), Petrology and geochemistry of oceanic and Alpine-type spinel peridotites in the context of the problem of mantle material evolution, Doctorate dissertation (Geol.Mineral.), p. 381, Vernadsky Institute of Geochemistry and Analytical Chemistry (GEOKHI), Russian Academy of Sciences, Moscow. (in Russian)

Bazylev, B. A., G. V. Ledneva, N. N. Kononkova, A. Ishiwatari (2013a), High-pressure ultramafics in the lower crustal rocks of the Pekul'ney Complex, central Chukchi Peninsula. 1. Petrography and mineralogy, Petrology, 21, No. 3, 221-248. doi:10.1134/S0869591113030028

Bazylev, B. A., G. V. Ledneva, A. Ishiwatari (2013b), Highpressure ultramafics in the lower crustal rocks of the Pekul'ney Complex, central Chukchi Peninsula. 2. Internal structure of blocks and ultramafic bodies, geologic and geodynamic setting of rock formation, Petrology, 21, No. 4, 336-350. doi:10.1134/S0869591113040024

Bazylev, B. A., K. V. Popov, V. P. Shcherbakov (2002), Petrographic features of oceanic peridotites as reflected by their magnetic characteristics, Russ. J. Earth Sci., 4, 211-223. doi:10.2205/2002ES000087

Bazylev, B. A., S. A. Silantyev, N. A Kononkova (1990), Metamorphism of hyperbasites in the oceanic crust, Magmatism and Tectonics of the Ocean (Lithos Project) p. 296-310, Nauka, Moscow.

Dunlop, D. J., M. Prevot (1982), Magnetic properties and opaque mineralogy of drilled submarine intrusive rocks, Geophys. J. R. Astr. Soc., 69, 763-802. doi:10.1111/j.1365246X.1982.tb02774.x

Kadzialko-Hofmokl, M., K. Delura, P. Bylina, M. Jelenska, J. Kruczyk (2008), Mineralogy and magnetism of Fe-Cr spinel series minerals from podiform chromitites and dunites from Tapadla (Sudetic ophiolite, SW Poland) and their relationship to palaeomagnetic results of the dunites, Geophys. J. Int., 175, 885-900. doi:10.1111/j.1365-246X.2008.03933.x

Kudryavtseva, G. P. (1988), Ferrimagnetism of Natural Oxides, 232 pp., Nedra, Moscow. (in Russian)

Nazarova, E. A., P. J. Wasilewski, H. J. Dick (2000), Magnetic study of serpentinized harzburgites from the Islas Orcadas Fracture Zone, Mar. Geophys. Res., 21, No. 5, 475-488. doi:10.1023/A:1026550011802

Nguen Thi Kim, Thoa, D. M. Pecherskii (1989), Serpentinites: A likely source of magnetic lineations, Izv. Akad. Nauk SSSR, Ser. Geol., 1, 61-67. (in Russian)

Popov, K. V., B. A. Bazylev, V. P. Shcherbakov (2006), Temperature range for magnetization of oceanic spinel peridotites, Oceanology, 46, No. 2, 256. doi:10.1134/S0001437006020123

Popov, K. V., B. A. Bazylev, V. P. Shcherbakov, A. K. Gapeev (2011), Comparison between the magnetic and petrological characteristics of the peridotites from the gorringe ridge and 
the peridotites from the Mid-Ocean Ridges, Oceanology, 51, No. 1, 157-169. doi:10.1134/S0001437011010140

Popov, K. V., V. P. Shcherbakov (1996), Petromagnetic characteristics of oceanic crustal rocks. Serpentinite, Nature of Magnetic Anomalies and the Inner Structure of the Oceanic Crust p. 82, VNIRO, Moscow. (in Russian)

Readman, P. W., W. O'Reilly (1972), Magnetic properties of oxidized (cation-deficient) titanomagnetites $(\mathrm{Fe}, \mathrm{Ti})_{3} \mathrm{O}_{4}, J$ Geomagn. Geoelectr., 24, 69-90. doi:10.5636/jgg.24.69

Robbins, M., G. K. Wertheim, R. C. Sherwood, et al. (1971), Magnetic properties and site distributions in the system $\mathrm{FeCr}_{2} \mathrm{O}_{4}-\mathrm{Fe}_{3} \mathrm{O}_{4}\left(\mathrm{Fe}_{2}+\mathrm{Cr}_{2}-\mathrm{xFex}_{3}+\mathrm{O}_{4}\right)$, J. Phys. Chem. Solids, 32, 717-729. doi:10.1016/S0022-3697(71)80412-2

Sack, R. O., M. S. Ghiorso (1991), Chromian spinels as petrogenetic indicators: thermodynamic and petrologic applications, American Mineralogist, 76, 827-847.

Shcherbakov, V. P., B. E. Lamash, V. V. Shcherbakova (1996), The nature of magnetization of oceanic crustal rocks, The $\mathrm{Na}$ ture of Magnetic Anomalies and the Structure of Oceanic Crust p. 7-34, All-Russia Research Institute of Fishery and Oceanography, Moscow.

Shcherbakova, V. V., V. P. Shcherbakov, Yu. K. Vinogradov (2008), pTRM properties as a function of the grain size and their manifestations in paleomagnetic experiments, Geophys. Stud., 9, No. 4, 5-29. (in Russian)

Thellier, B., O. Thellier (1955), Sur l'intensite du champ magnetique terrestre dans le passe, historique et geologique, Ann. Geophys., 15, 285-376.

Ziemniak, S. E., R. A. Castelli (2003), Immiscibility in the $\mathrm{Fe}_{3} \mathrm{O} 4-\mathrm{FeCr}_{2} \mathrm{O}_{4}$ spinel binary, J. Phys. Chem. Solids, 64, 2081-2091. doi:10.1016/S0022-3697(03)00237-3

B. A. Bazylev, N. N. Kononkova, Vernadsky Institute of Geochemistry and Analytical Chemistry (GEOKHI), Russian Academy of Sciences, Moscow

K. V. Popov, Shirshov Oceanology Institute, Russian Academy of Sciences, Moscow. (popov@ocean.ru)

V. A. Tsel'movich, Borok Geophysical Laboratory, Schmidt Joint Institute of Physics of the Earth, Russian Academy of Sciences, Borok

V. P. Shcherbakov, Borok Geophysical Laboratory, Schmidt Joint Institute of Physics of the Earth, Russian Academy of Sciences, Borok and Institute of Geology and Petroleum Technologies, Kazan (Volga region) Federal University, Russia 